Review

\title{
Artificial Intelligence Application in Solid State Mg-Based Hydrogen Energy Storage
}

\author{
Song-Jeng Huang (D), Matoke Peter Mose *(D) and Sathiyalingam Kannaiyan \\ Department of Mechanical Engineering, National Taiwan University of Science and Technology, No 43, Section 4, \\ Keelung Road, Taipei 106, Taiwan; sgighuang@mail.ntust.edu.tw (S.-J.H.); sathiaerospace@gmail.com (S.K.) \\ * Correspondence: peter.mose022@gmail.com; Tel.: +886-(2)-2733-3141 (ext. 7261)
}

Citation: Huang, S.-J.; Mose, M.P.; Kannaiyan, S. Artificial Intelligence Application in Solid State Mg-Based Hydrogen Energy Storage. J. Compos. Sci. 2021, 5, 145. https://doi.org/ $10.3390 /$ jcs5060145

Academic Editor: Vincenza Brancato

Received: 11 May 2021

Accepted: 27 May 2021

Published: 29 May 2021

Publisher's Note: MDPI stays neutral with regard to jurisdictional claims in published maps and institutional affiliations.

Copyright: (c) 2021 by the authors. Licensee MDPI, Basel, Switzerland. This article is an open access article distributed under the terms and conditions of the Creative Commons Attribution (CC BY) license (https:// creativecommons.org/licenses/by/ $4.0 /)$.

\begin{abstract}
The use of Mg-based compounds in solid-state hydrogen energy storage has a very high prospect due to its high potential, low-cost, and ease of availability. Today, solid-state hydrogen storage science is concerned with understanding the material behavior of different compositions and structure when interacting with hydrogen. Finding a suitable material has remained an elusive idea, and therefore, this review summarizes works by various groups, the milestones they have achieved, and the roadmap to be taken on the study of hydrogen storage using low-cost magnesium composites. Mg-based compounds are further examined from the perspective of artificial intelligence studies, which helps to improve prediction of their properties and hydrogen storage performance. There exist several techniques to improve the performance of $\mathrm{Mg}$-based compounds: microstructure modification, use of catalytic additives, and composition regulation. Microstructure modification is usually achieved by employing different synthetic techniques like severe plastic deformation, high energy ball milling, and cold rolling, among others. These synthetic approaches are discussed herein. In this review, a discussion of key parameters and operating conditions are highlighted in a view to finding high storage capacity and faster kinetics. Furthermore, recent approaches like machine learning have found application in guiding the experimental design. Hence, this review paper also explores how machine learning techniques have been utilized to fasten the materials research. It is however noted that this study is not exhaustive in itself.
\end{abstract}

Keywords: hydrogen storage; artificial intelligence; machine learning

\section{Introduction}

Human economic activity has grown tremendously since the advent of the 21st century. Due to this economic growth, mortality rates have slowed down, giving rise to a sharp increase in the global population [1]. Scientists have projected that the global population will grow to 10 billion by 2050 . Thus, to sustain such a population, there is an urgent need to look for sustainable energy sources that are clean and efficient [2].

Currently, more than $80 \%$ of the global energy and about $86 \%$ of US energy is from traditional fossil fuels that have resulted in environmental issues due to global warming. Key energy sector players such governments, researchers etc. are actively involved to ensure that there is a transition to clean and low-carbon sources [1-3]. Hydrogen has the requisite potential as an energy carrier which is not only clean but also cheap due to its abundance. While hydrogen has a high energy density, it can be difficult to store this light gas in a compact and secure manner. In this regard, energy materials researchers are much more concerned with the safety, storage capacity, uptake and conversion rates, and cost of renewables sources so that they can compete with fossil fuels and thus enhance a faster energy transition. This makes hydrogen storage the mainstream research in many countries. In regard to this, hydrogen can be stored in physical form or chemical form in metal hydrides like magnesium hydride $\left(\mathrm{MgH}_{2}\right)$ [4].

The research of hydrogen storage in magnesium alloys has been on an upscale expansion with the main goals being to develop a system with low cost, light weight, and fast 
kinetics. Formation of Mg-composites influences the hydrogen storage behavior, which majorly depend on the quantity of the second phase additive [5]. These parameters can be optimized by the use of catalyst elements, microstructure manipulation, and systematic study of release rates by determining the rate-limiting factors [4]. The synthesis of nanoporous materials such as complex chemical hydrides, metal-doped carbon-based nanomaterials, carbon based nanomaterials, metallic hydrides, and metal organic frameworks (MOFs) paved the way for hydrogen study. Under complex working conditions, these materials have varying degrees of physisorption and chemisorption rates [6].

In general, solid-state hydrogen storage has the disadvantages of low storage capacity and high cost. Thus, the development of new materials is critical; however, the method takes a long time due to novel trial and error techniques. According to Luo et al. [7], the timeconsuming nature of materials science derives from diverse research goals, dependence on personal knowledge, and, of course, trial and error. Recent breakthroughs in machine learning have aided in improving the analytical approach to materials science. Existing material behavior can be used to forecast other useful parameters before conducting experiments, lowering costs, and speeding up the testing process. "Machine learning (ML) is a subset of Artificial intelligence that can determine patterns from a dataset without being explicitly programmed to recognize those patterns" [8].

ML approaches are needed to classify top-performing materials from a pool in a timely and accurate manner [9]. Rapid machine learning implementation has transformed dataset development in many fields, including industry, healthcare, and science. This technology has seen ground-breaking advancements in autonomous driving, image recognition, and target tracking, as well as speech recognition. In machine learning, the inputs are referred to as features, and the target is referred to as the label. Unsupervised, supervised, and reinforcement learning are the three types of ML.

This review summarizes the common synthetic techniques applied to effectively enhance solid-state hydrogen storage in Mg-composites. In addition, the development of artificial intelligence to the investigation of Mg-based hydrogen storage materials is also discussed. It is used to provide a straightforward blueprint for the machine learning approaches used to perform a feasible research.

\section{Technical Limitations of Mg-Based Hydrogen Storage}

The use of Mg-based materials for onboard hydrogen storage has several drawbacks. These drawbacks include slow kinetics and an undesirable desorption temperature [10]. The idea that solid-state hydrogen storage would be important in the future transportation field derives from the low working pressure that will offer high protection.

Improvement of these properties has already been studied using manual laboratory techniques such as severe plastic deformation [11-15] high energy ball milling [11,16-18] composition and structural control [19], and the usage of catalysts [20]. In addition, multiscale modelling has been used.

\section{Hydrogen Storage Investigation Methods}

The methods specified for hydrogen storage investigations are experimental and multiscale modelling. Multiscale modelling involves the application of varying levels of theory in cognizant of the length scales and time evolution of the phenomenon being researched. Hydrogen absorption has been modelled before using these multiscale techniques.

To achieve the goal in these techniques, computations to relate molecular interactions and potential energies are necessary and are done through Density Functional Theory (DFT) [21-23], Quantum Mechanics (QM), or Molecular Dynamics (MD) [24] and Monte Carlo Simulations. The computations involved become huge when the length scales increase, which puts the accuracy into question [25]. 
Recently, the deployment of artificial intelligence in hydrogen energy storage has been done by ML techniques to do the predictions. ML techniques provide a faster and cheaper alternative to the multiscale modelling techniques, and hence they are the main focus of this review.

\subsection{Experimental Enhancement Techniques}

In the experimental techniques, many research groups have worked on severe plastic deformation and high energy ball milling to enhance the hydrogen storage performance of Mg-based compounds.

\subsubsection{Severe Plastic Deformation}

Equal channel angular pressing (ECAP) and cold rolling (CR) are the primary techniques for severe plastic deformation. The ECAP technology is described elsewhere [26]. It is reported that severe plastic deformation enhances the hydrogen storage properties of Mg-based compounds by modifying their microstructure [15]. This modification is achieved by its influence on the grain size, phase stability, introduction of defects, and texture. Grain size plays a key role in the absorption and desorption kinetics of the solid state hydrogen storage. This stems from its ability to affect the physical, mechanical and chemical aspects of polycrystalline metals [27]. Thus, grain refinement is beneficial in designing a material with desirable properties for enhanced performance.

Scripnyuk et al. [28] conducted the first recorded severe plastic deformation work on bulk Mg-based materials for hydrogen storage improvement. Scripnyuk and colleagues researched ZK60 magnesium alloy, where they used ECAP to press a billet. The billet was pressed in 8 passes at $300{ }^{\circ} \mathrm{C}$ in a $120^{\circ}$ die with no rotation. The results showed an initial grain size of $46 \mu \mathrm{m}$ reducing to $0.5-2 \mu \mathrm{m}$. This was discovered to greatly increase the rates of hydrogen absorption and desorption. They attributed the improvement to the effect of ECAP on microstructure uniformity, the small grains, and defect structure.

According to Chiu C. et al. [12], the method of processing the metal matrix composites has an effect of their hydrogen storage behavior. In addition, from their studies on AZ31 $\mathrm{Mg}$-based composites, pure alloy processed via 8 passes of ECAP can store $7.0 \mathrm{wt} \% \mathrm{H}_{2}$, however this capacity is reduced for a composite of the same alloy composition.

Soyama and coworkers [29] characterized the performance of a ZK60 composite produced by the addition of 2.5 wt percent mischmetal $(\mathrm{Mm})$ and processed by ECAP. This study demonstrates that Mm creates a network of intermetallic particles at the grain boundaries of the ZK60 alloy. Following deformation of these particles, the hydrogen storage efficiency was improved. In contrast to the work of Asselli A.A.C et al. [30], which is depicted in Figures 1 and 2, the formation of a composite phase improved the activation behavior and the hydrogen storage capacity. ZK60 without Mm absorbed less than $4 \mathrm{wt} \%$ $\mathrm{H}_{2}$ in $24 \mathrm{~h}$, while $\mathrm{ZK} 60$ with $\mathrm{Mm}$ absorbed up to $4.77 \mathrm{wt} \% \mathrm{H}_{2}$ before grinding and $6.4 \mathrm{wt} \%$ $\mathrm{H}_{2}$ after grinding in the same conditions. Despite the positive effects of $\mathrm{Mm}$ inclusion, it was discovered that it reduces the air resistance of ZK60.

While studying the effect of second phase particles of Y on ZK60 Mg alloy, Song Y. et al. [31] showed that second phase particles results in a microstructure of fine grains.

\subsubsection{Mechanical Milling}

Mechanical milling was identified as the most effective methods for producing nanocomposites and nanocrystalline metal alloys with sizes ranging from 30 to $50 \mathrm{~nm}$ [32]. Furthermore, magnesium alloys with nanometer grain sizes produced by high energy ball milling (HEBM) exhibited improved behavior when subjected to high temperatures for stabilization, resulting in improvements in mechanical properties [33-36]. There is already a lot of evidence that nanosizing is a viable solution that could lead to the development of functional hydrogen storage materials with high capacity and cycling capability near the ambient temperature. These observed improvements in hydrogen properties are the result of interrelated parameters associated with particle size. 


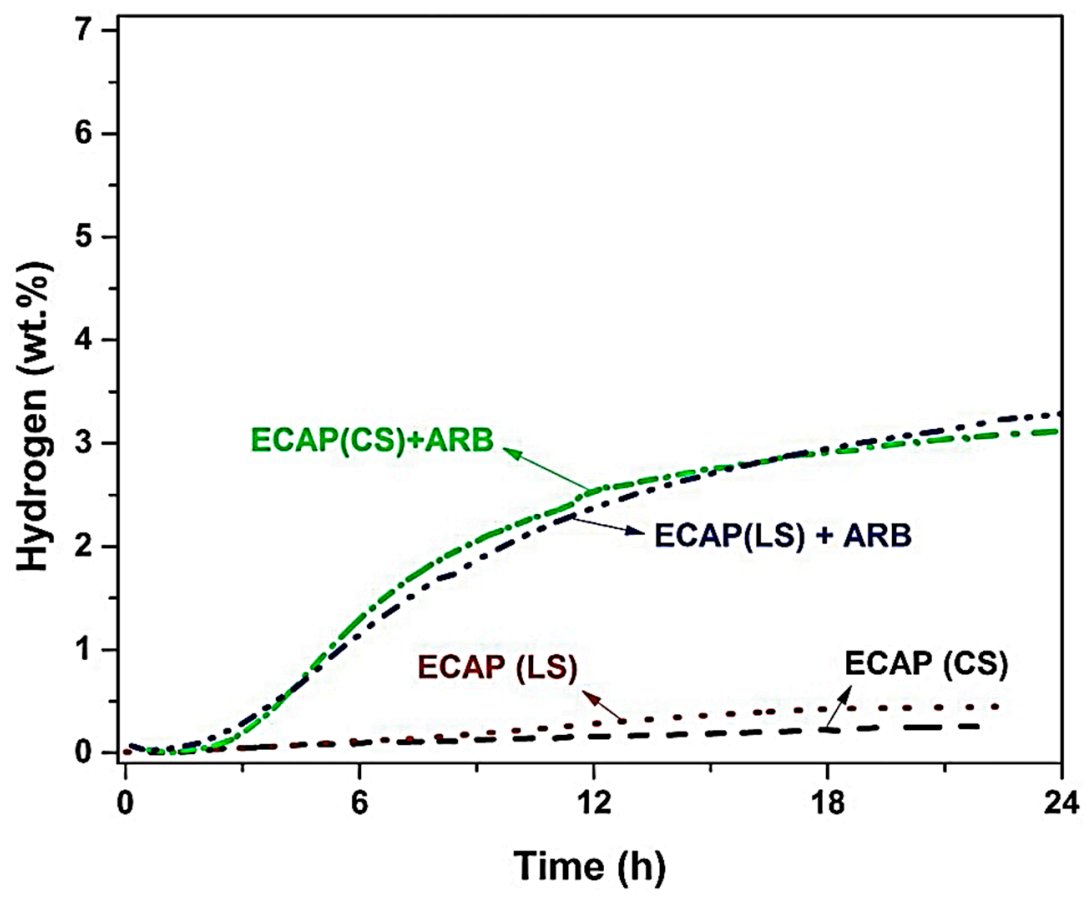

Figure 1. Kinetic curves of ZK60 without Mm. Reprinted with permission from Asselli A.A.C et al. (2015) Copyright 2015, Hydrogen Energy Publications.

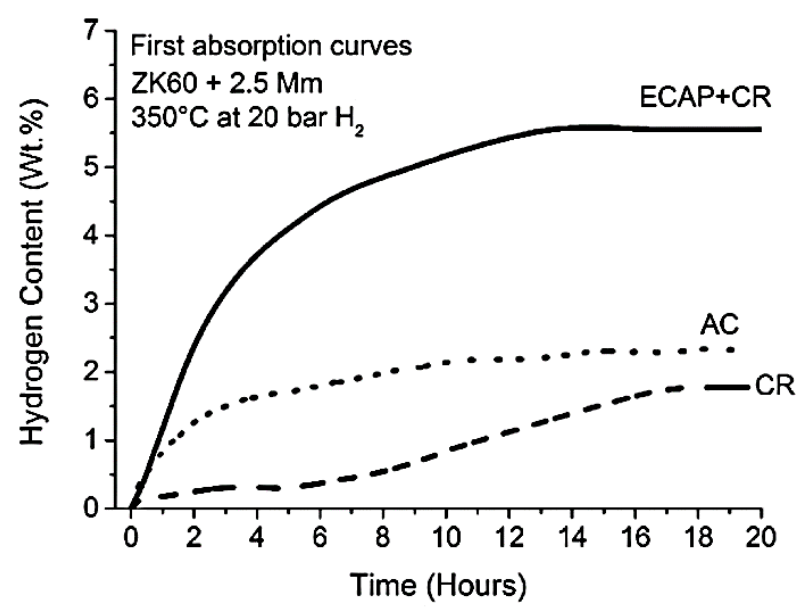

(a) Activation curves

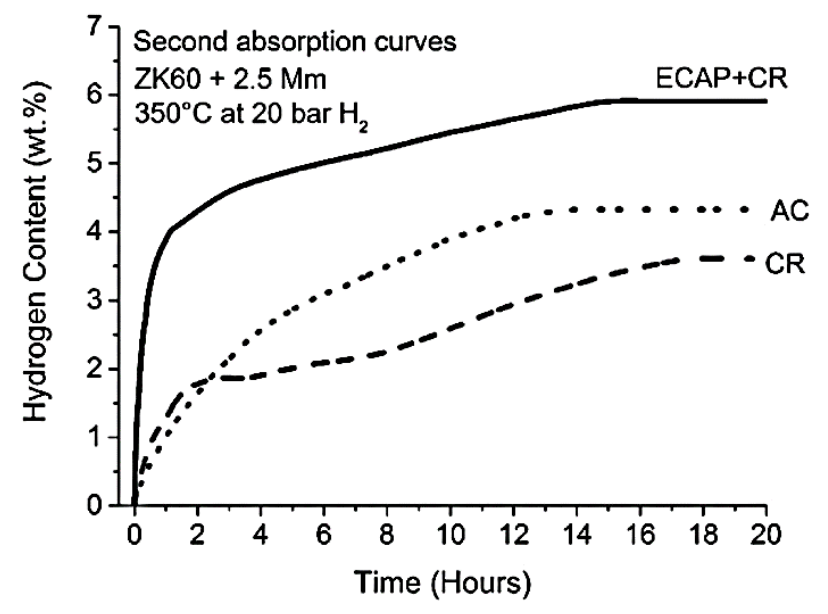

(b) Second absorption curves

Figure 2. Kinetic curves of ZK60 with Mm (a) activation; (b) Second absorption. Reprinted with permission from Soyama J et al. (2016) Copyright 2016, Hydrogen Energy Publications.

Song J.H. et.al Studied the influence by mechanical milling of the material and ball milling time of $\mathrm{Mg}$ on the microstructure of a Ti-Mg alloy. The observed peak broadening is caused by increasing milling time, and this phenomenon has a strong relation to an increase in lattice strain and a reduction in crystallite size. The cold-welding was small due to the low magnesium content, and the finer particle size was easily attained. The average size of the composite powder is influenced by the magnesium content and milling time intervals. By increasing the magnesium content, the time required for size refinement and the formation of a solid solution is extended [37].

A researcher investigated the effect of ball milling on the mechanical reaction of magnesium by reinforcing $\mathrm{Al}$ particles into the matrix. The ball milled aluminum particles were evenly distributed in the magnesium matrix. An increase in the content of ball milled 
aluminum particles resulted in clumping of reinforcing phase within the composite. In the composite, reinforcement clusters led to an increased content of ball-milled aluminum particles and a substantial increase in fracture work. The presence of micro cracks in $\mathrm{Al}$ particles is often associated to reinforcement cluster and contributed to the sudden drop due to failure strain [38].

Mechanically milled particles of AZ91D chips are flake-like in their structure, so that they are bound to large particles initially. As the process progresses, the particles are hardened and impacted, causing large particles to fragment and form smaller ones. Mechanically milled powder with smaller particle sizes and a broader size distribution can be achieved with shorter milling times and higher ball to powder ration (BPR). The best mechanically milled powder was obtained with a BPR of 25:1 and a milling time of $10 \mathrm{~h}[35,39]$.

Solid diffusion processes are enabled by decreased particle size during milling because the gaps between the components are minimized and the defects are denser, and plastic deformation increases the surface energy. As a result, the more effective the diffusion mechanism between the grains, the higher the elemental consolidation in the composite [40].

The rate of refinement of crystallite size slows as milling time increases, which is directly related to the thermal effect during the milling period. During the milling process, Ti particles were repeatedly deformed and fragmented, which eventually refined the size of Ti particles. The high-energy milling operation, on the other hand, not only decreased Ti particle size but also tended to remove sharp edges, resulting in a rounded Ti particle morphology. The mechanically milled Ti-added AZ31 Mg alloy had a significantly higher micro hardness and yield strength [41].

With the inclusion of stearic acid, the AZ91 powders were greatly refined after mechanical milling. During mechanical milling, stearic acid adsorbs on the surface of the material, reducing the possibility of cold welding between powder particles. The $\beta$-phase steadily dispersed evenly in the magnesium matrix during milling. The volume of $\beta$-phase decreased as the mechanical milling time increased [42].

Ball milling is the main preparation method for processing magnesium-based composites for hydrogen storage, resulting in interdiffusion and alloying reactions between various elements of varying grain sizes [32]. The pure and reactive surfaces in dislocations and crystal defects created by high-energy ball milling will provide a wide variety of $\mathrm{H}$ diffusion routes, decreasing the time and duration of $\mathrm{H}$ diffusion, enhancing the composite hydrogen absorption kinetics [43].

The size of the milled composite is slightly smaller and has greater energy. The milling at dry conditions also leads to a reduction in particle size compared to prepared composites with heptane. The composites milled in dry conditions showed that the hydriding kinetics improved significantly at low temperatures. The melted composites showed a rapid deterioration in capacity during the cycling period in the presence of heptane, which showed an efficient carbon coating process [44].

\subsection{Machine Learning (ML) Techniques and Applications}

The use of ML has been widely applied to handle complex problems. This stems from the fact that they learn easily from the examples and have the capability to handle noise, incomplete data, and nonlinearity problems. In determining material properties, predictive analysis is useful in saving the costs of running traditional experiments. Since predictions are usually interpolative in nature, they require samples of the material properties which are then mapped by an algorithm to learn [45-47]. Kim E. et al. [48] reviewed the synthesis parameters for different alloys and composites from twelve thousand publications. Their goal was to illustrate the capability of transfer learning via machine learning to forecast a methodology and required parameters for materials synthesis in hydrogen storage. They reported that this approach allows one to investigate the synthesis parameters of specific materials at large scales. 
A convolutional neural network was trained by Sohn and colleagues [49] on simulated $\mathrm{XRD}$ results, to be used to distinguish phases of different material compositions. The model was able to recognize both phases and composition after training. On evaluating the model, it attained 99.5 percent precision. Similar models have been used in the synthesis and characterization of new materials [50].

ML algorithms have been used to extend the screening of MOFs for hydrogen gas storage. This technique promises precision and speed in predicting chemical properties of MOFs compared to determinist approaches. However, the precision is limited by the sample size used during training and testing [51-53].

Materials with multiple phase systems that undergo reversible phase changes under the influence of temperature are considered safe for hydrogen storage. From recent research [54], machine learning was used to upscale the effects of temperature without the use of phonon computations. The researchers emphasize that this model will benefit any number of combinations of elements in the search for new phases that are stable. The authors concluded that the analysis of activation energy for phase shift and kinetically dependent transformations can be scaled using ML to characterize the behavior of unexploited compositional spaces.

ANN has seen large applications in prediction of mechanical properties od Al-Znmagnesium alloys and composites. Dobrzański and coworkers [55] performed experiments with $\mathrm{Mg}$ alloys and the tested results were applied in designing of ANN to predict mechanical properties. The challenges in the ANN model were found in preprocessing the variables. Similarly, Kalogirou S.A et al. [56] described the various applications of artificial neural network (ANN models). They pointed out that ANN has a wide application in energy prediction, energy consumption optimization and forecasting. In the application of ANN, data from past history and performance of the real system and empirical selection of suitable model are essential. Learning takes place when the inputs are introduced together with the targets as shown in Figure 3.

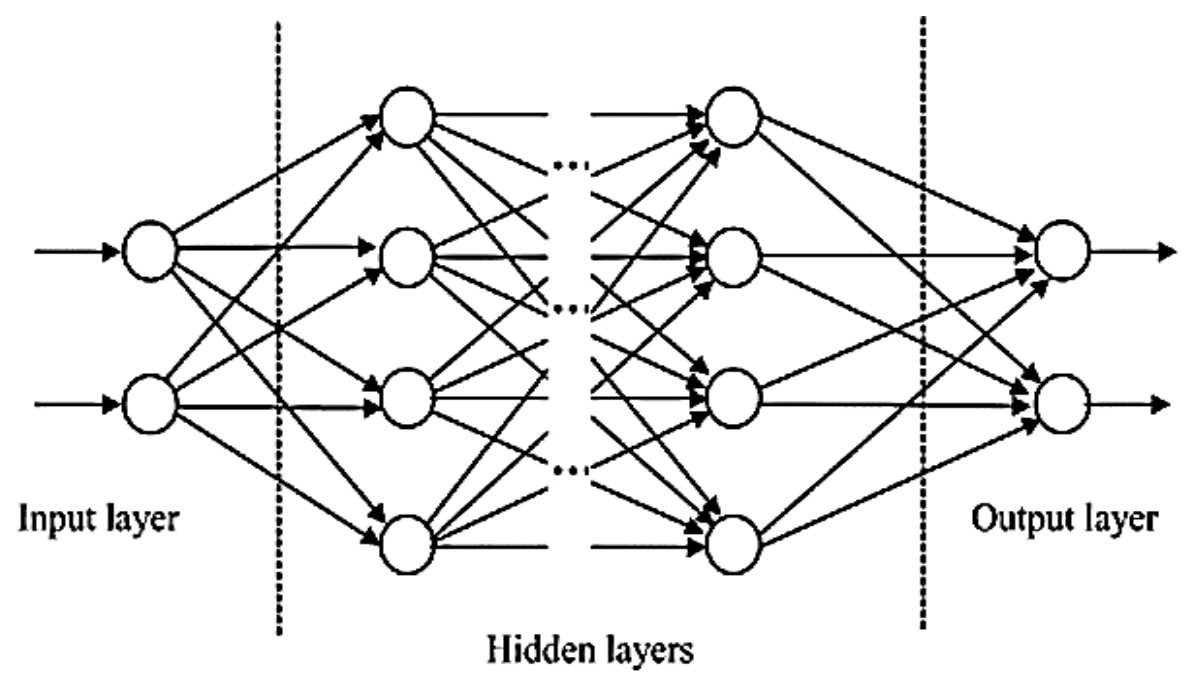

Figure 3. Neural Network schematics. Reprinted with permission from Soteris A. Kalogirou (2001) Copyright 2001 Elsevier Science Ltd.

Yaici and Entchev [57] also applied ANN for prediction of solar thermal energy system. The input parameters were heat values from solar collectors. The output predicted were the temperature distribution of the tank and solar savings fraction. Two variants of back-propagation algorithm were used: levenberg-marguardt (LM) and scaled conjugate gradient (SCG). LM was shown to be an optimal algorithm with prediction errors of less than $\pm 3 \%$ against SCG with $\pm 5 \%$ error.

Tian Q. et al. [58] used artificial neural networks to predict the life cycle performance of hydrogen storage in magnesium alloys. The experimental cycle life data for various 
Mg-based alloys were used to train the network. The first five cycles were used as the inputs while the last 15 cycles were used as the output in the training process. Because the cycle life was estimated with the substitution of elements, it was found that the cycle life slightly improves.

The error optimization was done using the LM back propagation algorithm. Tian and coworkers [58] confirmed the results with experimental data and established that it was consistent with the predictions. Therefore, this method can be used to predict cycle stability of the materials beyond the 20 cycles used.

Rahnama and Sridhar [59] employed K-means algorithm of the unsupervised machine learning techniques to analyze the behavior of various material groups and how they influence the percentage and operating parameters of hydrogen storage. Three main clusters were established from a list of eight. From this clustering analysis, it was evident that samples with same structures were classified in the three classes. The study also points out that temperature and enthalpy are crucial parameters in the clustering of materials. This study shows a high correlation between temperature, pressure, and hydrogen weight percent of the three materials classes: $\mathrm{A}_{2} \mathrm{~B}$, complex, and Mg-based alloys. Hence, this technique could be used to find a material with close chemical properties. The method is very fast; however, it is limited to the local minima. Experience shows that the limitation can be overcome by iterating the process several times.

Rahnama A. et al. [60] used supervised machine learning to rate attributes that are critical for the study of hydrogen storage percent. Neural networks, linear and Bayesian regressions, and boosted decision tree algorithms were used. Their work shows that a comparison of the score labels gives better performance in boosted decision tree algorithm which achieved $83 \%$ determination coefficient as shown in Table 1.

Table 1. Performance evaluation of the regression models in hydrogen storage (wt.\%) prediction. Reprinted with permission from Rahnama et al., (15 March 2019) Copyright 2019, Hydrogen Energy Publications LLC.

\begin{tabular}{ccccc}
\hline Metric & $\begin{array}{c}\text { Boosted Decision } \\
\text { Tree Regression }\end{array}$ & $\begin{array}{c}\text { Bayesian Linear } \\
\text { Regression }\end{array}$ & $\begin{array}{c}\text { Neural Network } \\
\text { Regression }\end{array}$ & Linear Regression \\
\hline Mean Absolute Error & 0.00303986 & 0.0442909 & 0.00482648 & 0.0417627 \\
Root Mean Squared Error & 0.0117862 & 0.092928 & 0.0682209 & 0.0787835 \\
Relative Absolute Error & 0.217859 & 0.571785 & 0.623087 & 0.539147 \\
Coefficient of Determination & 0.83 & 0.569095 & 0.608113 & 0.502114 \\
\hline
\end{tabular}

The database used by the researchers did not contain binary hydrides that are widely reported in literature. The properties of 2722 hydrides used include hydrogen weight percent and the formation enthalpy $(\Delta \mathrm{H})$. Rahnama and co-workers report that for one to forecast the hydrogen storage capacity, the knowledge of the material class, temperature, enthalpy, and pressure is required.

Li J. et al. [61] discussed the development of Mg-based materials for hydrogen storage through downsizing and catalysis. In downsizing, the authors have pointed out that reduction in grain size can be achieved by thin film synthesis, plasma reactions, high energy ball milling, and catalyzed reactions. Here, the essence of downsizing is to achieve optimal desorption temperatures and faster hydrogen absorption/desorption kinetics. From their discussion, it is clear that small size leads to shortened diffusion and dissociation lengths, and increased surface energies, both of which have a positive impact on the kinetics.

Since the kinetics of magnesium are slow, they usually require high temperature and pressure to absorb and release hydrogen. To improve these properties, catalytic additives are used. In hydrogen storage research, catalyst and other additives are usually used to enhance the sorption kinetics of hydrogen in a material. Thus, catalyst discovery would play a major role that would enhance faster materials research for hydrogen storage.

Consequently, Williams T. et al. [8] used a small experimental dataset together with machine learning (scikit-learn package) to predict the catalyst performance. They discov- 
ered that machine learning is a valuable tool for solving complex correlations in catalytic systems, and that it can be used to forecast future catalyst results.

Unsupervised machine learning methods were used to demonstrate correlations in content groups in a report by Alireza R. and Seetharaman S. [59]. The metal hydride clusters of $\mathrm{A}_{2} \mathrm{~B}$, complex hydrides, and $\mathrm{Mg}$-based alloys were discovered to be in the same cluster in their analysis due to sharing the same structure. Similar features were used to investigate the hydrogen weight percentage and how it correlates to operating parameters such as temperature and pressure. Zhao D. and coworkers [62] used ensemble machine learning to predict the desorption rates of $\mathrm{LiBH}_{4}$-based mixtures. They wanted to infer established relationships between variables and hydrogen release amount in their research. Despite the fact that they used a bi-component catalyst, their results suggest that the approach is stable and can be used for prediction.

This method is limited by the hyper-parameter tuning which proves most effective when random forecast algorithm is used as shown in Figure 4. Random forecast uses ensemble decision trees for predictions. Even though the process was applied to ammonia decomposition experiment, the model can be extended to hydrogen storage. The results demonstrate that the performance of a catalyst depends on the composition and the quantity added. The requirement of small number of experiments to conduct predictions proves both time saving and cost effective and thus faster material discovery. Therefore, machine learning reduces the number of experiments by optimizing the method design.

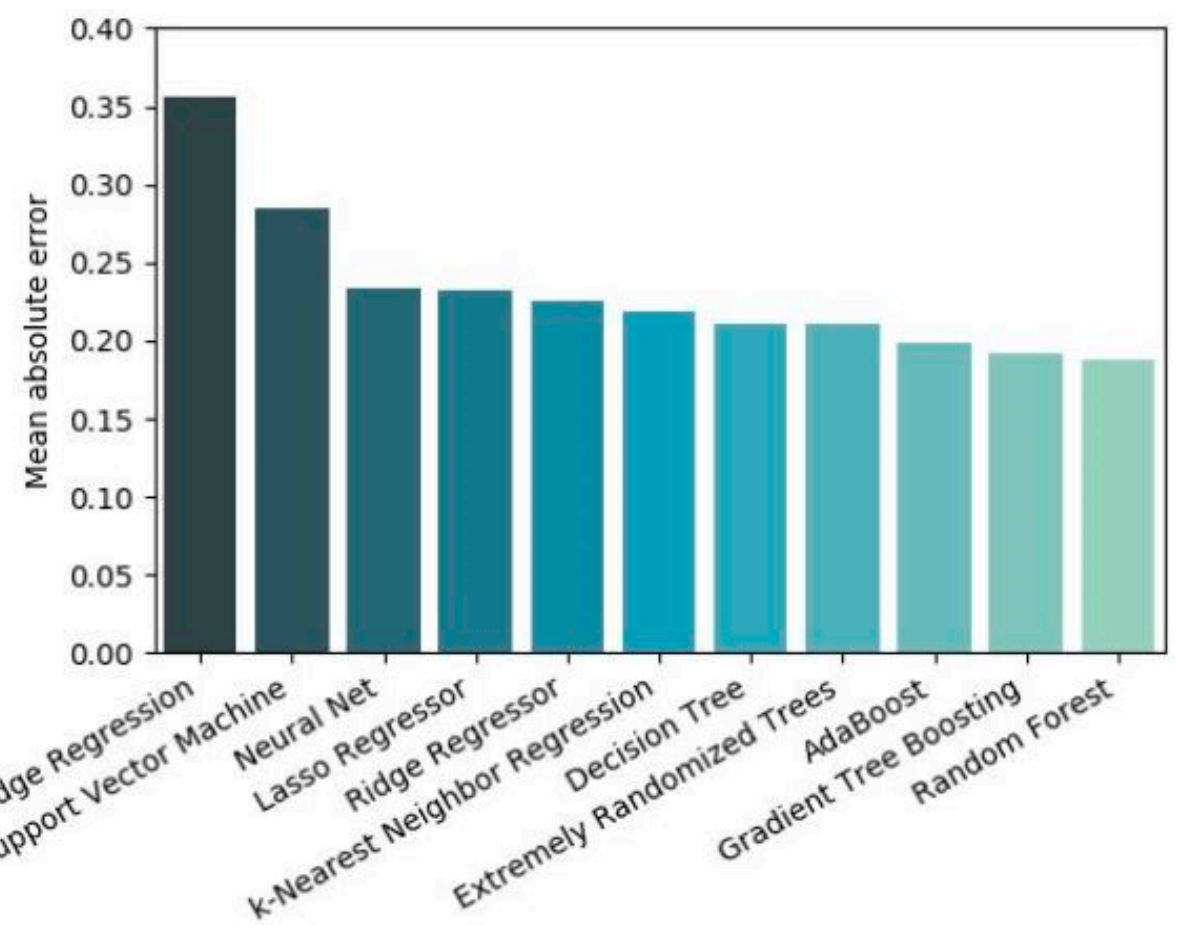

Figure 4. Machine learning algorithms performance comparison [7]. Reprinted with permission from Williams T. et al. (2020) Copyright 2020, American Chemical Society.

Malinova T. et al. [63] worked on modelling an ANN to predict the storage capacity of hydrogen in magnesium alloys. They further modeled the dehydrogenation parameters and their correlation with alloy composition. The model was trained using LM algorithm. The researchers reported that increasing the alloying content would result in a lower hydrogen storage capacity; however, alloy additives have been widely reported to lower the desorption temperature. It has been reported that increasing the amount of aluminum increases the hydrogen weight percent. The addition of Ni lowers both the operating conditions of desorption, which is a one-of-a-kind result. 


\section{Discussion of the Synthetic Techniques and Their Effect on Hydrogen Storage Performance and Limitations}

The methods introduced in this review provide a basis for evaluating the hydrogen performance of various composites of magnesium. Despite the aims being different, the end result is to improve the hydrogen storage of the material as summarized in Tables 2 and 3.

Table 2. Comparison of ECAP performance on different $\mathrm{Mg}$ alloys and composites.

\begin{tabular}{|c|c|c|c|c|}
\hline Material & Process & Aim & Results & Reference \\
\hline ZK60 & $\begin{array}{l}\text { ECAP } \\
8 \text { passes }\end{array}$ & Minimize grain size & $\begin{array}{ll}- & 0.12 \mathrm{wt} \% \mathrm{H}_{2} / \mathrm{min} \text { at } 300{ }^{\circ} \mathrm{C} \\
- & \text { Capacity: } 7 \mathrm{wt} \% \mathrm{H}_{2} \\
\text { - } & 250 \mathrm{~nm} \text { grain size achieved } \\
\text { - } & \text { Stability after } 4 \text { cycles }\end{array}$ & [11] \\
\hline $\mathrm{AZ} 31+\mathrm{AC}+\mathrm{Ni}$ & $\begin{array}{l}\text { ECAP } \\
8 \text { passes }\end{array}$ & $\begin{array}{l}\text { Route and number of } \\
\text { pass optimization }\end{array}$ & $\begin{array}{ll}- & 0.094 \mathrm{wt} \% \mathrm{H}_{2} / \mathrm{min} \text { at } 375{ }^{\circ} \mathrm{C} \\
\text { - } & \text { Capacity: } 7 \mathrm{wt} \% \mathrm{H}_{2} \\
\text { - } & \text { Stability after } 5 \text { cycles } \\
\text { - } & \text { Route } \mathrm{B}_{\mathrm{C}} \text { at } 8 \text { passes has smallest grain size }\end{array}$ & [12] \\
\hline AZ31 & $\begin{array}{l}\text { ECAP } \\
4 \text { passes }\end{array}$ & $\begin{array}{l}\text { Influence of texture } \\
\text { for hydrogen storage }\end{array}$ & $\begin{array}{ll}- & 0.0044 \mathrm{wt} \% \mathrm{H}_{2} / \mathrm{min} \text { at } 300{ }^{\circ} \mathrm{C} \\
- & \text { Capacity: } 4 \mathrm{wt} \% \mathrm{H}_{2} \\
\text { - } & \text { Route A, Achieved grain size: } 960 \mathrm{~nm} \\
\text { - } & (0001) \text { texture is most preferred for hydrogen storage }\end{array}$ & [64] \\
\hline AZ61 & $\begin{array}{c}\text { ECAP } \\
8 \text { passes }\end{array}$ & Influence of ECAP & $\begin{array}{ll}\text { - } & 0.15 \mathrm{wt} \% \mathrm{H}_{2} / \mathrm{min} \text { at } 3755^{\circ} \mathrm{C} \\
\text { - } & \text { Capacity: } 6.2 \mathrm{wt} \% \mathrm{H}_{2}\end{array}$ & [13] \\
\hline $\mathrm{AZ} 61+\mathrm{Ni}+\mathrm{SiC}$ & $\begin{array}{c}\text { ECAP } \\
4 \text { passes }\end{array}$ & Influence of additive & $\begin{array}{ll}\text { - } & 0.33 \mathrm{wt} \% \mathrm{H}_{2} / \mathrm{min} \text { at } 375^{\circ} \mathrm{C} \\
\text { - } & \text { Capacity: } 6.8 \mathrm{wt} \% \mathrm{H}_{2}(\text { no } \mathrm{Ni}), 6.5 \mathrm{wt} \% \mathrm{H}_{2} \text { (with } \mathrm{Ni} \text { ) }\end{array}$ & [14] \\
\hline
\end{tabular}

Table 3. Different processing parameters for ball milling in the hydrogen absorption of Mg-composites.

\begin{tabular}{|c|c|c|c|c|}
\hline Sample Material & Milling Time (Hours) & BPR $^{1}$ & Hydrogen Storage Properties (wt $\%$ ) & Reference \\
\hline AZ31-3 wt\%G (Graphene) & 4 & $30: 1$ & Abs: $6.83 \pm 0.04$ & [18] \\
\hline AZ31-4 wt $\% \mathrm{Ni}$ & 3 & $30: 1$ & Abs: $7.0 \pm 0.04$ & [17] \\
\hline $\mathrm{MgH}_{2}-4 \mathrm{wt} \% \mathrm{Ni}$ & 10 & $40: 1$ & Des: 7.0 & [65] \\
\hline $\mathrm{MgH}_{2}-1 \mathrm{~mol}^{\circ} \mathrm{C}_{60}$ & 2 & $21: 1$ & Abs: 5.1 & {$[66]$} \\
\hline Mg-2 wt\%graphite & 4 & $20: 1$ & $\begin{array}{l}\text { Abs: } 6.0 \\
\text { Des: } 4.5\end{array}$ & [67] \\
\hline Mg-2 wt $\%$ MWCNTs & 0.5 & $20: 1$ & $\begin{array}{l}\text { Abs: } 6.5 \\
\text { Des: } 6.5\end{array}$ & [67] \\
\hline $\mathrm{Mg}-10 \mathrm{wt} \% \mathrm{LaCl} 3$ & 1 & $30: 1$ & Abs:5.1 & [68] \\
\hline $\mathrm{Mg}-5$ wt. $\% \mathrm{Ni}$ & 30 & $11: 1$ & Des: 5.47 & [69] \\
\hline
\end{tabular}

Key: Abs: absorption; Des: desorption. ${ }^{1}$ BPR-Ball to powder ratio.

According to the results of the studies presented in Table 2, storage capacity is not temperature dependent, but sorption rates are. Reducing grain size was discovered to improve sorption kinetics, which was attributed to the fact that diffusion along grain boundaries is faster than surface diffusion along bulk material. It was also reported that the processing route has no effect on storage capacity, however, the addition of a catalyst and an increase in the number of ECAP passes increases both storage capacity and kinetics. The disadvantage of using powders for hydrogen measurements has been reported to be poor conductivity.

The use of ECAP as a processing technique faces numerous challenges due to the multiple parameters that must be optimized, including the ECAP route, extrusion temperature, die angle, number of passes, and sample orientation. This constraint allows machine 
learning to collect data of the best conditions from reported data, allowing it to optimize and speed up the experimentation process.

On the other hand, ball milling is also used to achieve reduction in both the grain size and particle size. This effect results in reduced diffusion lengths for hydrogen during absorption and desorption. However, to achieve small scales that have faster kinetics, long milling times are required as depicted in Table 3. Besides, it also suffers the disadvantage of determining which number of milling durations give the optimum results. Several parameters are involved in the milling process, including the type of ball mill, the BPR, milling frequency, time, pressure and milling atmosphere $\left(\mathrm{Ar} / \mathrm{H}_{2}\right)$, and volume ratio. The vast number of parameters, and the fact that they are not often properly recorded, make it impossible to compare findings from materials synthesized by various research groups.

The data from various researchers in the preceding discussion help to elucidate that machine learning has fewer limitations in the scope of application such as compositional use, material clusters, and computation time. Table 4 summarizes the advantages and disadvantages of each method.

Table 4. Comparison of experimental techniques and machine learning.

\begin{tabular}{|c|c|c|}
\hline Method & Advantages & Disadvantages \\
\hline Experimental & - Easy to use on laboratory scale & $\begin{array}{l}\text { - Mostly trial and error } \\
\text { - } \quad \text { Rely on personal experience }\end{array}$ \\
\hline Machine learning & $\begin{array}{l}\text { - } \quad \text { Can be used to evaluate large scales } \\
\text { - } \quad \text { Can be used to exploit unexplored } \\
\text { compositional space } \\
\text { - Able to predict parameters for materials } \\
\text { with similar chemical properties. }\end{array}$ & $\begin{array}{l}\text { - } \quad \text { Most widely reported data is for binary hydrides. } \\
\text { - } \quad \text { Limited by the training sample size } \\
\text { be cumbersome. }\end{array}$ \\
\hline
\end{tabular}

\section{Conclusions}

According to the findings of this review, grain size has a significant impact on the absorption and desorption kinetics of solid-state hydrogen storage. Mm forms an intermetallic particle network at the grain boundaries of the ZK60 alloy, according to the review data. As a result, the formation of a composite phase improved the activation behavior and hydrogen storage capability of the material.

Ball milling is the most common method of preparing magnesium-based composites for hydrogen storage. When exposed to high temperatures for stabilization, nanometer grain size composites produced by high energy ball milling demonstrated improved behavior. At low temperatures, the hydriding kinetics of the dry milled composites changed dramatically. As milling time increases, the rate of refinement of crystallite size slows, which is directly related to the thermal effect during the milling period. It has also been reported that severe plastic deformation can improve hydrogen storage properties by systematically altering the microstructure and introducing defects. Ball milling is indeed a better process to synthesize nanocomposites. However, there is no homogeneity in the reported results to ascertain the limit of ball milling due to existence of many variables.

It has been demonstrated in this review that an experimental database is required when performing cross-validation of the ML performance evaluation. ML typically requires a large dataset during training, but studies have shown that smaller datasets can be used.

The research presented in this review shows that ML can be used to investigate hydrogen storage performance in $\mathrm{Mg}$-based alloys and composites. The applications range from synthesis to characterization to energy storage prediction. ML, for example, can be trained on a variety of datasets and, once trained, can be used to predict trends that may be useful in the redevelopment of hydrogen energy materials. However, the present review finds that ML use in the study of Mg-composites has few reported works. Therefore, more studies to determine the limit of ball milling are needed. 
The use of AI in hydrogen storage has revealed that, given the materials clusters generated by ML, it is possible to use classes of materials with similar chemical structures to predict the properties of a different material in the same class. Besides, ML studies show that temperature and enthalpy of desorption are critical attributes for studying hydrogen storage capacity. The hydrogen weight percent is also highly correlated with operating conditions. Furthermore, researchers have reported that the composition of an alloy and the weight percent added influence the weight of hydrogen stored in a material. This demonstrates that ML has enormous potential in the study of Mg-composites.

Author Contributions: Conceptualization, S.-J.H. and M.P.M; investigation, S.K. and M.P.M; resources, S.-J.H., M.P.M. and S.K.; writing, original draft preparation, M.P.M.; writing, review and editing, S.-J.H. and S.K.; visualization, M.P.M.; supervision, S.J.H. All authors have read and agreed to the published version of the manuscript.

Funding: This research received no external funding.

Conflicts of Interest: The authors declare no conflict of interest.

\section{References}

1. Sun, Y.; Shen, C.; Lai, Q.; Liu, W.; Wang, D.-W.; Aguey-Zinsou, K.-F. Tailoring magnesium based materials for hydrogen storage through synthesis: Current state of the art. Energy Storage Mater. 2018, 10, 168-198. [CrossRef]

2. World Bank. Inclusive Green Growth; World Bank: Washington, DC, USA, 2012.

3. Muradov, N.; Veziroglu, T. “Green” path from fossil-based to hydrogen economy: An overview of carbon-neutral technologies. Int. J. Hydrogen Energy 2008, 33, 6804-6839. [CrossRef]

4. Crivello, J.-C.; Dam, B.; Denys, R.V.; Dornheim, M.; Grant, D.M.; Huot, J.; Jensen, T.R.; De Jongh, P.; Latroche, M.; Milanese, C.; et al. Review of magnesium hydride-based materials: Development and optimisation. Appl. Phys. A 2016, 122, 1-20. [CrossRef]

5. Lototskyy, M.; Sibanyoni, J.; Denys, R.; Williams, M.; Pollet, B.G.; Yartys, V. Magnesium-carbon hydrogen storage hybrid materials produced by reactive ball milling in hydrogen. Carbon 2013, 57, 146-160. [CrossRef]

6. Boateng, E.; Chen, A. Recent advances in nanomaterial-based solid-state hydrogen storage. Mater. Today Adv. $2020,6,100022$. [CrossRef]

7. Luo, Z.; Yang, X.; Wang, Y.; Liu, W.; Liu, S.; Zhu, Y.; Huang, Z.; Zhang, H.; Dou, S.; Xu, J.; et al. A Survey of Artificial Intelligence Techniques Applied in Energy Storage Materials R\&D. Front. Energy Res. 2020, 8. [CrossRef]

8. Williams, T.; McCullough, K.; Lauterbach, J.A. Enabling Catalyst Discovery through Machine Learning and High-Throughput Experimentation. Chem. Mater. 2019, 32, 157-165. [CrossRef]

9. Fanourgakis, G.S.; Gkagkas, K.; Tylianakis, E.; Froudakis, G.E. Fast Screening of Large Databases for Top Performing Nanomaterials Using a Self-Consistent, Machine Learning Based Approach. J. Phys. Chem. C 2020, 124, 19639-19648. [CrossRef]

10. Shao, H.; He, L.; Lin, H.; Li, H.-W. Progress and Trends in Magnesium-Based Materials for Energy-Storage Research: A Review. Energy Technol. 2018, 6, 445-458. [CrossRef]

11. Krystian, M.; Zehetbauer, M.; Kropik, H.; Mingler, B.; Krexner, G. Hydrogen storage properties of bulk nanostructured ZK60 Mg alloy processed by Equal Channel Angular Pressing. J. Alloys Compd. 2011, 509, S449-S455. [CrossRef]

12. Chiu, C.; Huang, S.-J.; Chou, T.-Y.; Rabkin, E. Improving hydrogen storage performance of AZ31 Mg alloy by equal channel angular pressing and additives. J. Alloys Compd. 2018, 743, 437-447. [CrossRef]

13. Huang, S.-J.; Chiu, C.; Chou, T.-Y.; Rabkin, E. Effect of equal channel angular pressing (ECAP) on hydrogen storage properties of commercial magnesium alloy AZ61. Int. J. Hydrogen Energy 2018, 43, 4371-4380. [CrossRef]

14. Huang, S.-J.; Mose, M.P.; Rajagopal, V. Effect of microstructure on the hydrogenation behavior of AZ61 magnesium alloy with silicon carbide and nickel additives, processed by equal channel angular pressing. Int. J. Hydrogen Energy 2021, 46, 4211-4221. [CrossRef]

15. Huot, J.; Skryabina, N.Y.; Fruchart, D. Application of Severe Plastic Deformation Techniques to Magnesium for Enhanced Hydrogen Sorption Properties. Metals 2012, 2, 329-343. [CrossRef]

16. Kurko, S.; Rašković, Ž.; Novaković, N.; Mamula, B.P.; Jovanović, Z.; Baščarević, Z.; Novaković, J.G.; Matović, L. Hydrogen storage properties of $\mathrm{MgH}_{2}$ mechanically milled with $\alpha$ and $\beta$ SiC. Int. J. Hydrogen Energy 2011, 36, 549-554. [CrossRef]

17. Huang, S.-J.; Rajagopal, V.; Ali, A.N. Influence of the ECAP and HEBM processes and the addition of Ni catalyst on the hydrogen storage properties of AZ31-x Ni (x=0,2,4) alloy. Int. J. Hydrogen Energy 2019, 44, 1047-1058. [CrossRef]

18. Huang, S.-J.; Rajagopal, V.; Chen, Y.L.; Chiu, Y.-H. Improving the hydrogenation properties of AZ31-Mg alloys with different carbonaceous additives by high energy ball milling (HEBM) and equal channel angular pressing (ECAP). Int. J. Hydrogen Energy 2020, 45, 22291-22301. [CrossRef]

19. Andreasen, A. Hydrogenation properties of Mg-Al alloys. Int. J. Hydrogen Energy 2008, 33, 7489-7497. [CrossRef]

20. Ma, T.; Isobe, S.; Wang, Y.; Hashimoto, N.; Ohnuki, S. Nb-Gateway for Hydrogen Desorption in Nb2O5 Catalyzed MgH2 Nanocomposite. J. Phys. Chem. C 2013, 117, 10302-10307. [CrossRef] 
21. Tao, S.X.; Notten, P.H.; Van Santen, R.A.; Jansen, A.P. DFT studies of hydrogen storage properties of Mg0.75Ti0.25. J. Alloys Compd. 2011, 509, 210-216. [CrossRef]

22. Ramírez-Dámaso, G.; Ramírez-Platón, I.; López-Chávez, E.; Castillo-Alvarado, F.; Cruz-Torres, A.; Caballero, F.; MondragónGuzmán, R.; Rojas-Hernández, E. A DFT study of hydrogen storage on surface (110) of Mg1-xAlx $(0 \leq \mathrm{x} \leq 0.1)$. Int. J. Hydrogen Energy 2016, 41, 23388-23393. [CrossRef]

23. Er, S. Hydrogen Storage Materials: A First-Principles Study; Universiteit Twente-Department of Science, Technology and Policy Studies (STePS): Twente, The Netherlands, 2009.

24. Bucior, B.J.; Bobbitt, N.S.; Islamoglu, T.; Goswami, S.; Gopalan, A.; Yildirim, T.; Farha, O.K.; Bagheri, N.; Snurr, R.Q. Energy-based descriptors to rapidly predict hydrogen storage in metal-organic frameworks. Mol. Syst. Des. Eng. 2018, 4, 162-174. [CrossRef]

25. Hirscher, M.; Yartys, V.A.; Baricco, M.; von Colbe, J.B.; Blanchard, D.; Bowman, R.C.; Broom, D.P.; Buckley, C.E.; Chang, F.; Chen, P.; et al. Materials for hydrogen-based energy storage-past, recent progress and future outlook. J. Alloys Compd. 2020, 827, 153548. [CrossRef]

26. Wang, L.; Jiang, J.; Ma, A.; Li, Y.; Song, D. A Critical Review of Mg-Based Hydrogen Storage Materials Processed by Equal Channel Angular Pressing. Metals 2017, 7, 324. [CrossRef]

27. Sheik Hassan, M.; Sharma, S.; Kumar, B. A Review of Severe Plastic Deformation. Int. Refereed J. Eng. Sci. 2017, 6, 66-85.

28. Skripnyuk, V.; Rabkin, E.; Estrin, Y.; Lapovok, R. The effect of ball milling and equal channel angular pressing on the hydrogen absorption/desorption properties of Mg-4.95 wt\% Zn-0.71 wt\% Zr (ZK60) alloy. Acta Mater. 2004, 52, 405-414. [CrossRef]

29. Soyama, J.; Triques, M.R.M.; Leiva, D.R.; Junior, A.M.J.; Da Silva, E.P.; Pinto, H.C.; Bolfarini, C.; Kiminami, C.S.; Botta, W.J. Hydrogen storage in heavily deformed ZK60 alloy modified with 2.5 wt.\% Mm addition. Int. J. Hydrogen Energy 2016, 41, 4177-4184. [CrossRef]

30. Asselli, A.; Leiva, D.; Huot, J.; Kawasaki, M.; Langdon, T.; Botta, W. Effects of equal-channel angular pressing and accumulative roll-bonding on hydrogen storage properties of a commercial ZK60 magnesium alloy. Int. J. Hydrogen Energy 2015, 40, 16971-16976. [CrossRef]

31. Song, Y.; Wang, M.; Zong, Y.; He, R.; Jin, J. Grain Refinement by Second Phase Particles under Applied Stress in ZK60 Mg Alloy with Y through Phase Field Simulation. Materials 2018, 11, 1903. [CrossRef]

32. Lyu, J.; Lider, A.; Kudiiarov, V. Using Ball Milling for Modification of the Hydrogenation/Dehydrogenation Process in MagnesiumBased Hydrogen Storage Materials: An Overview. Metals 2019, 9, 768. [CrossRef]

33. Jabbari-Taleghani, M.; Torralba, J.M. Hot workability of nanocrystalline AZ91 magnesium alloy. J. Alloys Compd. 2014, 595, 1-7. [CrossRef]

34. Wen-Bin, F.; Wa, F.; Hong-Fei, S. Preparation of high-strength Mg-3Al-Zn alloy with ultrafine-grained microstructure by powder metallurgy. Powder Technol. 2011, 212, 161-165. [CrossRef]

35. Suryanarayana, C. Mechanical alloying and milling. Prog. Mater. Sci. 2001, 46, 1-184. [CrossRef]

36. Chaubey, A.; Scudino, S.; Khoshkhoo, M.S.; Prashanth, K.; Mukhopadhyay, N.; Mishra, B.; Eckert, J. High-strength ultrafine grain $\mathrm{Mg}-7.4 \% \mathrm{Al}$ alloy synthesized by consolidation of mechanically alloyed powders. J. Alloys Compd. 2014, 610, 456-461. [CrossRef]

37. Huang, S.J.; Muneeb, A.; Abbas, A.; Sankar, R. The effect of Mg content and milling time on the solid solubility and microstructure of Ti-Mg alloys processed by mechanical milling. J. Mater. Res. Technol. 2021, 11, 1424-1433. [CrossRef]

38. Habibi, M.K.; Tun, K.S.; Gupta, M. An investigation into the effect of ball milling of reinforcement on the enhanced mechanical response of magnesium. J. Compos. Mater. 2011, 45, 2483-2493. [CrossRef]

39. Nikmardan, S.; Pouyafar, V. Fabrication of AZ91D/SiCp composites by mechanical milling of magnesium alloy chips and spark plasma sintering in a semi-solid regime. J. Asian Ceram. Soc. 2019, 7, 154-160. [CrossRef]

40. Galindez, Y.; Correa, E.; Zuleta, A.A.; Valencia-Escobar, A.; Calderon, D.; Toro, L.; Chacón, P. Improved Mg-Al-Zn Magnesium Alloys Produced by High Energy Milling and Hot Sintering. Met. Mater. Int. 2021, 27, 1113-1130. [CrossRef]

41. Zhou, H.; Hu, L.; Sun, Y.; Zhang, H.; Duan, C.; Yu, H. Synthesis of nanocrystalline AZ31 magnesium alloy with titanium addition by mechanical milling. Mater. Charact. 2016, 113, 108-116. [CrossRef]

42. Su, S.; Zhou, J.; Tang, S.; Yu, H.; Su, Q.; Zhang, S. Synthesis of Nanocrystalline AZ91 Magnesium Alloy Dispersed with 15 vol.\% Submicron SiC Particles by Mechanical Milling. Materials 2019, 12, 901. [CrossRef]

43. Li, Z.; Liu, X.; Jiang, L.; Wang, S. Characterization of Mg-20wt\% Ni-Y hydrogen storage composite prepared by reactive mechanical alloying. Int. J. Hydrogen Energy 2007, 32, 1869-1874. [CrossRef]

44. Stoyadinova, H.; Zlatanova, Z.; Spassova, M.; Spassov, T.; Baklanov, M. Influence of Milling Conditions on the Hydriding Properties of Mg-C Nanocomposites. J. Nanomater. 2015, 2015, 1-6. [CrossRef]

45. Ramprasad, R.; Batra, R.; Pilania, G.; Mannodi-Kanakkithodi, A.; Kim, C. Machine learning in materials informatics: Recent applications and prospects. NPJ Comput. Mater. 2017, 3, 54. [CrossRef]

46. Witman, M.; Ling, S.; Grant, D.M.; Walker, G.S.; Agarwal, S.; Stavila, V.; Allendorf, M.D. Extracting an Empirical Intermetallic Hydride Design Principle from Limited Data via Interpretable Machine Learning. J. Phys. Chem. Lett. 2019, 11, 40-47. [CrossRef]

47. Raccuglia, P.; Elbert, K.C.; Adler, P.D.F.; Falk, C.; Wenny, M.B.; Mollo, A.; Zeller, M.; Friedler, S.A.; Schrier, J.; Norquist, A.J. Machine-learning-assisted materials discovery using failed experiments. Nat. Cell Biol. 2016, 533, 73-76. [CrossRef] [PubMed]

48. Kim, E.; Huang, K.; Saunders, A.; McCallum, A.; Ceder, G.; Olivetti, E. Materials Synthesis Insights from Scientific Literature via Text Extraction and Machine Learning. Chem. Mater. 2017, 29, 9436-9444. [CrossRef] 
49. Lee, J.-W.; Park, W.B.; Singh, S.P.; Sohn, K.-S. A deep-learning technique for phase identification in multiphase inorganic compounds using synthetic XRD powder patterns. Nat. Commun. 2020, 11, 1-11. [CrossRef]

50. Selvaratnam, B.; Koodali, R.T. Machine learning in experimental materials chemistry. Catal. Today 2021, 371, 77-84. [CrossRef]

51. Borboudakis, G.; Stergiannakos, T.; Frysali, M.; Klontzas, E.; Tsamardinos, I.; Froudakis, G.E. Chemically intuited, large-scale screening of MOFs by machine learning techniques. NPJ Comput. Mater. 2017, 3, 1-6. [CrossRef]

52. Anderson, G.; Schweitzer, B.; Anderson, R.; Gómez-Gualdrón, D.A. Attainable Volumetric Targets for Adsorption-Based Hydrogen Storage in Porous Crystals: Molecular Simulation and Machine Learning. J. Phys. Chem. C 2018, 123, 120-130. [CrossRef]

53. Zhang, X.; Zhang, K.; Lee, Y. Machine Learning Enabled Tailor-Made Design of Application-Specific Metal-Organic Frameworks. ACS Appl. Mater. Interfaces 2020, 12, 734-743. [CrossRef]

54. Clary, J.M.; Holder, A.M.; Musgrave, C.B. Computationally Predicted High-Throughput Free-Energy Phase Diagrams for the Discovery of Solid-State Hydrogen Storage Reactions. ACS Appl. Mater. Interfaces 2020, 12, 48553-48564. [CrossRef] [PubMed]

55. Króll, M. Neural network application for prediction mechanical properties of Mg-Al-Zn alloys. Arch. Comput. Mater. Sci. Surf. Eng. 2010, 2, 181-188.

56. Kalogirou, S.A. Artificial neural networks in renewable energy systems applications: A review. Renew. Sustain. Energy Rev. 2001, 5, 373-401. [CrossRef]

57. Yaici, W.; Entchev, E. Performance prediction of a solar thermal energy system using artificial neural networks. Appl. Therm. Eng. 2014, 73, 1348-1359. [CrossRef]

58. Tian, Q.; Zhang, Y.; Wu, Y.; Tan, Z. The cycle life prediction of Mg-based hydrogen storage alloys by artificial neural network. Int. J. Hydrogen Energy 2009, 34, 1931-1936. [CrossRef]

59. Rahnama, A.; Sridhar, S. Application of data science tools to determine feature correlation and cluster metal hydrides for hydrogen storage. Materialia 2019, 7, 100366. [CrossRef]

60. Rahnama, A.; Zepon, G.; Sridhar, S. Machine learning based prediction of metal hydrides for hydrogen storage, part II: Prediction of material class. Int. J. Hydrogen Energy 2019, 44, 7345-7353. [CrossRef]

61. Li, J.; Li, B.; Shao, H.; Li, W.; Lin, H. Catalysis and Downsizing in Mg-Based Hydrogen Storage Materials. Catalysts 2018, 8, 89. [CrossRef]

62. Ding, Z.; Chen, Z.; Ma, T.; Lu, C.-T.; Ma, W.; Shaw, L. Predicting the hydrogen release ability of LiBH4-based mixtures by ensemble machine learning. Energy Storage Mater. 2020, 27, 466-477. [CrossRef]

63. Malinova, T.; Guo, Z.X. Artificial neural network modelling of hydrogen storage properties of Mg-based alloys. Mater. Sci. Eng. A 2004, 365, 219-227. [CrossRef]

64. Jorge, A.M.; Prokofiev, E.; de Lima, G.F.; Rauch, E.; Veron, M.; Botta, W.J.; Kawasaki, M.; Langdon, T.G. An investigation of hydrogen storage in a magnesium-based alloy processed by equal-channel angular pressing. Int. J. Hydrogen Energy 2013, 38, 8306-8312. [CrossRef]

65. Chen, M.; Xiao, X.; Zhang, M.; Liu, M.; Huang, X.; Zheng, J.; Zhang, Y.; Jiang, L.; Chen, L. Excellent synergistic catalytic mechanism of in-situ formed nanosized $\mathrm{Mg} 2 \mathrm{Ni}$ and multiple valence titanium for improved hydrogen desorption properties of magnesium hydride. Int. J. Hydrogen Energy 2019, 44, 1750-1759. [CrossRef]

66. Alsabawi, K.; Gray, E.; Webb, C. The effect of ball-milling gas environment on the sorption kinetics of MgH2 with/without additives for hydrogen storage. Int. J. Hydrogen Energy 2019, 44, 2976-2980. [CrossRef]

67. Popilevsky, L.; Skripnyuk, V.; Beregovsky, M.; Sezen, M.; Amouyal, Y.; Rabkin, E. Hydrogen storage and thermal transport properties of pelletized porous $\mathrm{Mg}-2 \mathrm{wt}$ \% multiwall carbon nanotubes and $\mathrm{Mg}-2 \mathrm{wt} \%$ graphite composites. Int. J. Hydrogen Energy 2016, 41, 14461-14474. [CrossRef]

68. Ismail, M. Effect of $\mathrm{LaCl} 3$ addition on the hydrogen storage properties of MgH 2. Energy 2015, 79, 177-182. [CrossRef]

69. Zaldívar-Cadena, A.; Díaz-Peña, I.; Cabañas-Moreno, J. Dispersion of niquel on the microstructure in magnesium based alloys for hydrogen storage. J. Magnes. Alloys 2013, 1, 292-296. [CrossRef] 